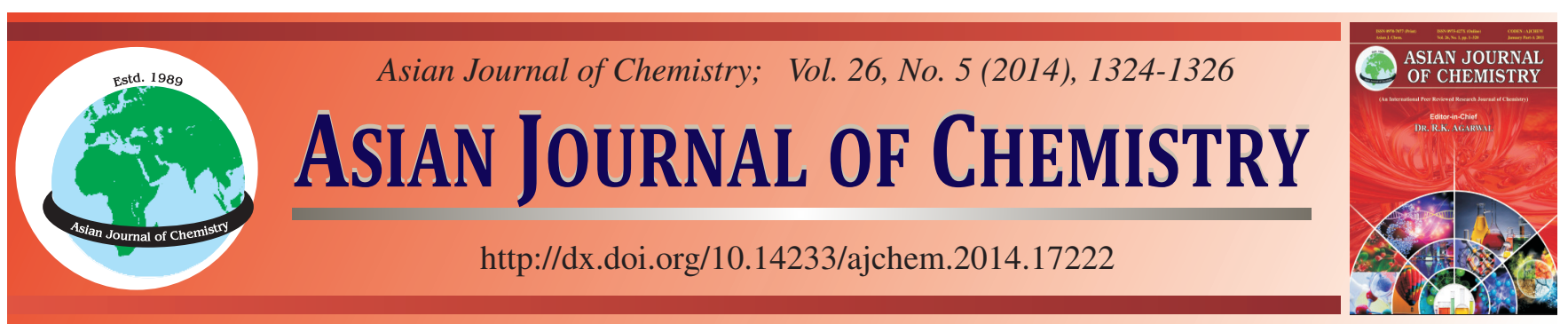

\title{
Study on Fluorine-Containing Polyurethane Elastomers Based on 2,2-Bis[4-(4-amino-2-trifluoromethylphenoxy)phenyl]hexafluoropropane $\dagger$
}

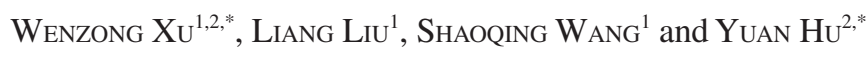

${ }^{1}$ School of Materials Science and Chemical Engineering, Anhui Jianzhu University, 856 Jinzai Road, Hefei 230022, Anhui Province, P.R. China ${ }^{2}$ State Key Lab of Fire Science, University of Science and Technology of China, Hefei 230026, Anhui Province, P.R. China

*Corresponding author: E-mail: wenzongxu@ sohu.com; yuanhu@ustc.edu.cn

\begin{abstract}
A series of fluorine-containing polyurethane elastomers (FPUEs) were synthesized from 2,2-bis[4-(4-amino-2-trifluoromethylphenoxy)phenyl]hexafluoropropane $\left(\mathrm{BAFPF}_{6} \mathrm{P}\right)$, which was made from 2-chlorobenzotrifluoride and 2,2-bis(4-hydroxyphenyl) hexafluoropropane and characterized by Fourier transform infrared spectroscopy, nuclear magnetic resonance, thermogravimetric analysis, microscale combustion colorimeter and contact angle measurement. The results show that the fluorine-containing polyurethane elastomers prepared from $\mathrm{BAFPF}_{6} \mathrm{P}$ have good thermal stability and low surface tension. Furthermore, fluorine-containing polyurethane elastomers also exhibit good flame retardance and the peak heat release rate and total heat released of fluorine-containing polyurethane elastomer based on $\mathrm{BAFPF}_{6} \mathrm{P}$ are much lower than those of polyurethane elastomer without the fluorine element.
\end{abstract}

Keywords: Fluorinated diamine, Fluorinated polyurethane elastomer, Surface properties, Flame retardancy.

\section{INTRODUCTION}

Polyurethane (PU) is widely applied in synthetic leathers, coatings, foams, adhesives, sealants, etc. due to its excellent properties. Fluorinated polyurethane (FPU) not only maintains the excellent properties of polyurethane but is also noted for some outstanding features such as low surface tension, low water absorption and good thermal stability; consequently, since the first patent about fluorinated polyurethane was published, it has attracted many scientists to do research in this area ${ }^{1-4}$.

In this study, a series of fluorine-containing polyurethane elastomers (FPUEs) were synthesized from 2,2-bis[4-(4amino-2-trifluoromethylphenoxy)phenyl] hexafluoropropane $\left(\mathrm{BAFPF}_{6} \mathrm{P}\right)$ which was made from 2-chlorobenzotrifluoride and 2,2-bis(4-hydroxyphenyl)hexafluoropropane. The structure of $\mathrm{BAFPF}_{6} \mathrm{P}$ was characterized by Fourier transform infrared (FTIR) and nuclear magnetic resonance (NMR) and the surface tension, thermostability and flame retardancy of FPUEs were investigated.

\section{EXPERIMENTAL}

Synthesis of fluorinated polyurethane elastomers: Polyester diol was heated to $110^{\circ} \mathrm{C}$, stirred and vacuumed for $2 \mathrm{~h}$ to remove trace water. When the temperature was reduced to $70{ }^{\circ} \mathrm{C}$, TDI was added and reacted for $2 \mathrm{~h}$. The prepolymer was prepared. The synthesis route of $\mathrm{BAFPF}_{6} \mathrm{P}$ is given in Scheme-I.

The molten chain extender $\left(\mathrm{BAFPF}_{6} \mathrm{P}\right.$ or MOCA) and prepolymer were fully mixed, then the mixture was casted on a Teflon plate at $70{ }^{\circ} \mathrm{C}$ for $2 \mathrm{~h}$ and $115^{\circ} \mathrm{C}$ for another $2 \mathrm{~h}$. Thus, the FPUEs were synthesized. Table-1 provides a description of the FPUEs and polyurethane elastomer.

Characterization: The contact angles of water and ethylene glycol on FPUE were measured with a JCZ 2000 contact angle goniometer at room temperature by the sessile drop method. The surface tension is calculated through the following equations:

$$
\begin{aligned}
\gamma_{\mathrm{s}} & =\gamma_{\mathrm{s}}^{\mathrm{d}}+\gamma_{\mathrm{s}}^{\mathrm{p}} \\
\cos \theta & =\frac{2}{\gamma_{\mathrm{L}}}\left[\left(\gamma_{\mathrm{L}}^{\mathrm{d}} \gamma_{\mathrm{s}}^{\mathrm{d}}\right)^{1 / 2}+\left(\gamma_{\mathrm{L}}^{\mathrm{p}} \gamma_{\mathrm{s}}^{\mathrm{p}}\right)^{1 / 2}\right]-1
\end{aligned}
$$

where $\gamma_{s}$ is the elastomer surface tension, $\gamma^{d}$ is the dispersion component, $\gamma^{p}$ is the polar component, $\theta$ is the contact angle of polymer with liquid(water or ethylene glycol in this test), $\gamma_{\mathrm{H}_{2} \mathrm{O}}{ }^{\mathrm{d}}=21.8 \times 10^{-3} \mathrm{~N} / \mathrm{m}, \gamma_{\mathrm{H}_{2} \mathrm{O}}{ }^{\mathrm{P}}=51 \times 10^{-3} \mathrm{~N} / \mathrm{m}, \gamma_{\mathrm{EG}}{ }^{\mathrm{d}}=29.3 \times 10^{-3}$ $\mathrm{N} / \mathrm{m}, \gamma_{\mathrm{EG}}{ }^{\mathrm{P}}=19.0 \times 10^{-3} \mathrm{~N} / \mathrm{m}$.

$†$ Presented at The 7th International Conference on Multi-functional Materials and Applications, held on 22-24 November 2013, Anhui University of Science \& Technology, Huainan, Anhui Province, P.R. China 

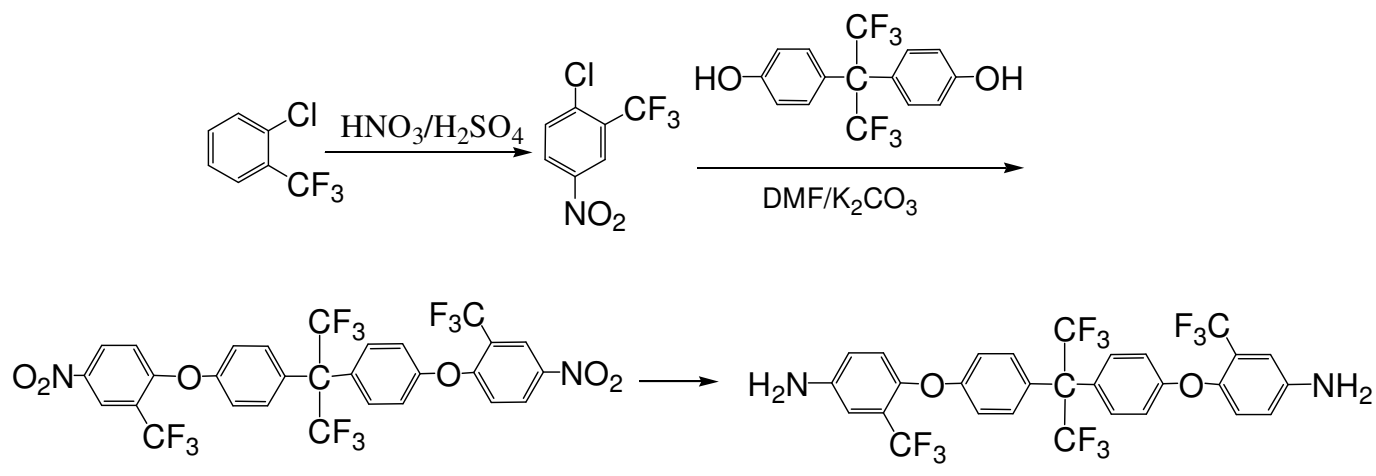

$\left(\mathrm{BNFPF}_{6} \mathrm{P}\right)$

$\left(\mathrm{BAFPF}_{6} \mathrm{P}\right)$

Scheme-I: Synthesis route of $\mathrm{BAFPF}_{6} \mathrm{P}$

\begin{tabular}{lcccc}
\multicolumn{5}{c}{ TABLE-1 } \\
& DESCRIPTION OF THE FPUES AND PUE \\
\hline Sample & Soft segment & R* & $\begin{array}{c}\text { Chain } \\
\text { extension } \\
\text { coefficient* }\end{array}$ & $\begin{array}{c}\text { Fluorine } \\
\text { content } \\
\text { wt.(\%) }\end{array}$ \\
\hline PUE & Polyester diol 1975 & 2.0 & 0.9 & 0 \\
FPUE1 & Polyester diol 1975 & 1.8 & 0.9 & 6.1 \\
FPUE2 & Polyester diol 1975 & 2.0 & 0.9 & 7.2 \\
FPUE3 & Polyester diol 1975 & 2.4 & 0.9 & 9.1 \\
\hline
\end{tabular}

* $\mathrm{R}$ is the molar ratios of $\mathrm{NCO}$ of TDI and $\mathrm{OH}$ of soft segment. *Chain extension coefficient is the molar ratios of $\mathrm{NH}_{2}$ of chain extender and $\mathrm{NCO}$ of prepolymer.

\section{RESULTS AND DISCUSSION}

Characterization of $\mathbf{B A F P F}_{6} \mathbf{P}$ : The chemical structures of $\mathrm{BNFPF}_{6} \mathrm{P}$ and $\mathrm{BAFPF}_{6} \mathrm{P}$ were identified by FTIR (Fig. 1), ${ }^{1} \mathrm{H}$ NMR (Fig. 2) and ${ }^{19} \mathrm{~F}$ NMR (Fig. 3).

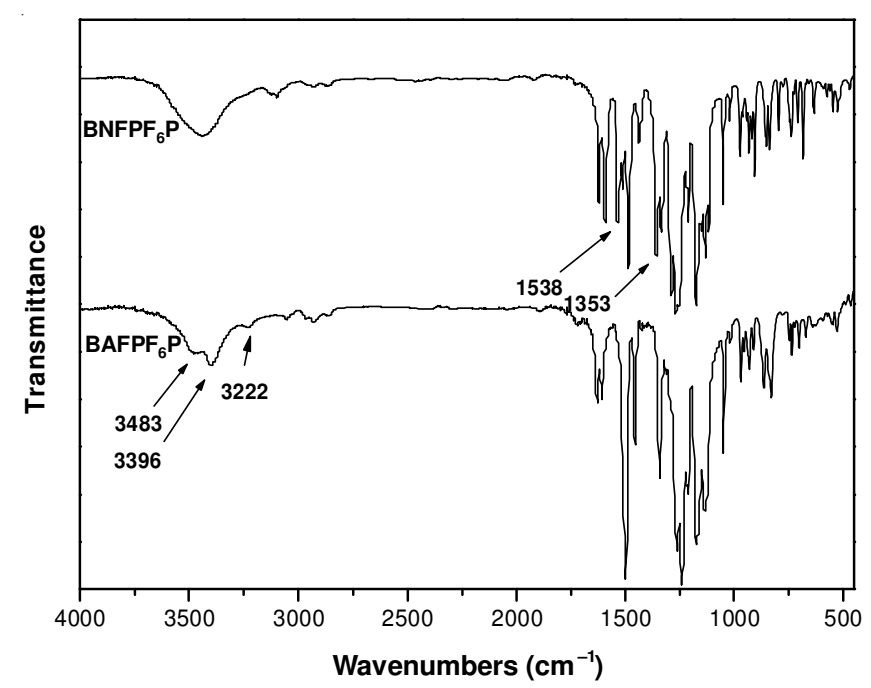

Fig. 1. FTIR spectra of $\mathrm{BNFPF}_{6} \mathrm{P}$ and $\mathrm{BAFPF}_{6} \mathrm{P}$

The FTIR of $\mathrm{BNFPF}_{6} \mathrm{P}$ in Fig. 1 shows that there are nitro absorption peaks at $1538 \mathrm{~cm}^{-1}$ which is from $-\mathrm{NO}_{2}$ asymmetric stretching and $1353 \mathrm{~cm}^{-1}$ which is from symmetric stretching. But the two peaks disappear in the FTIR of $\mathrm{BAFPF}_{6} \mathrm{P}$, which shows that the reduction of $-\mathrm{NO}_{2}$ has happened; In the meantime, the typical N-H stretching absorptions at 3483 and $3396 \mathrm{~cm}^{-1}, \mathrm{~N}-\mathrm{H}$ bending absorption at $1634 \mathrm{~cm}^{-1}$ are found in the FTIR of $\mathrm{BAFPF}_{6} \mathrm{P}$, which indicates the $-\mathrm{NH}_{2}$ has arisen.
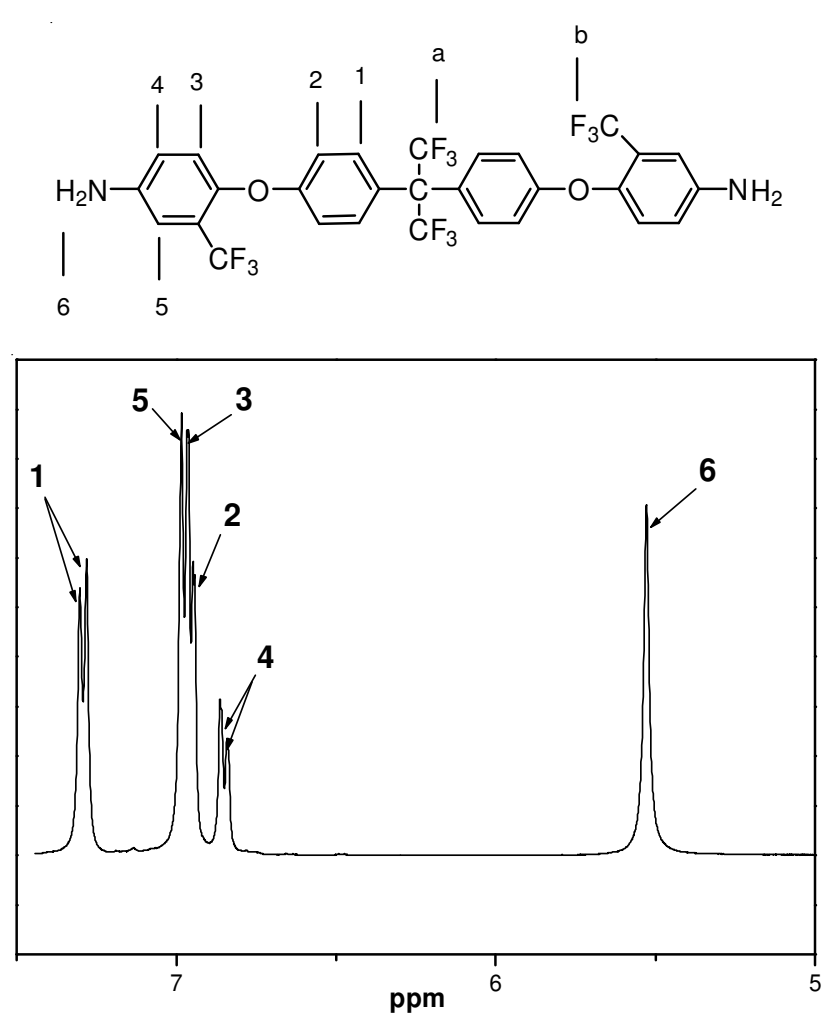

Fig. 2. ${ }^{1} \mathrm{H}$ NMR spectrum of $\mathrm{BAFPF}_{6} \mathrm{P}$

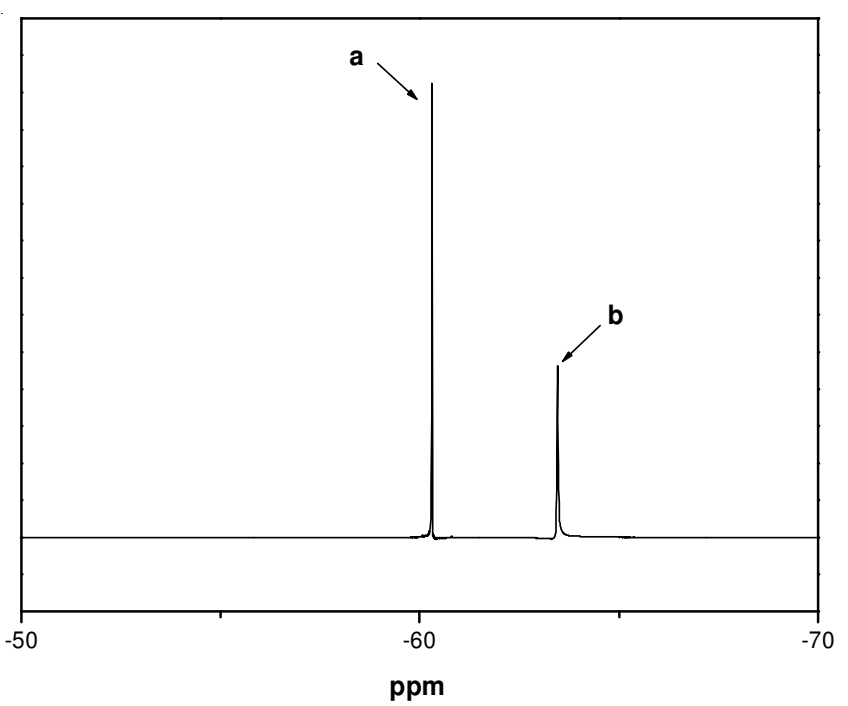

Fig. 3. ${ }^{19}$ F NMR spectrum of $\mathrm{BAFPF}_{6} \mathrm{P}$ 
All the above results indicate that $\mathrm{BNFPF}_{6} \mathrm{P}$ completely converts into $\mathrm{BAFPF}_{6} \mathrm{P}$. The peaks at $1502 \mathrm{~cm}^{-1}$ is a characteristic absorption peak of the benzene ring. The $\mathrm{C}-\mathrm{F}$ multiple stretch bending absorptions from $-\mathrm{CF}_{3}$ are observed between 1300 and $1100 \mathrm{~cm}^{-1}$.

The ${ }^{1} \mathrm{H}$ and ${ }^{19} \mathrm{~F}$ NMR of $\mathrm{BAFPF}_{6} \mathrm{P}$ are shown in Figs. 2 and 3 , respectively. The structure of $\mathrm{BAFPF}_{6} \mathrm{P}$ molecule is symmetrical and all the hydrogen can be divided into six types for different chemical environments. The ratio of the integral height of $\mathrm{H}_{1}: \mathrm{H}_{2}: \mathrm{H}_{3}: \mathrm{H}_{4}: \mathrm{H}_{5}: \mathrm{H}_{6}$ is $4: 4: 2: 2: 2: 4$, which is identical with the number of hydrogen atoms of $\mathrm{BAFPF}_{6} \mathrm{P}$. In Fig. 3, two peaks are found at -60.28 and $-63.44 \mathrm{ppm}$, indicating that the fluorine atoms are in two different chemical environments. The ratio of the integral height $\mathrm{Fa}$ and $\mathrm{Fb}$ is equal to 1, which is in accordance with that of the designed product.

Thermal property of FPUEs: $\mathrm{T}_{10}, \mathrm{~T}_{50}$ and $\mathrm{T}_{\max }$ are the temperature of $10 \%, 50 \%$ and max weight loss of the sample, respectively. The $\mathrm{T}_{10}$ and $\mathrm{T}_{50}$ of FPUE2 are higher than those of polyurethane elastomer, meanwhile the char yield of FPUE2 $(19.6 \%)$ is higher than that of PUE (14.9\%). It can be concluded that FPUE2 has a better thermal stability than PUE (Table-2).

\begin{tabular}{lccccc}
\multicolumn{7}{c}{ TABLE-2 } \\
\hline Sample & $\mathrm{T}_{10}$ & $\mathrm{~T}_{50}$ & $\mathrm{~T}_{\max 1}$ & $\mathrm{~T}_{\max 2}$ & $\begin{array}{c}\text { Char yield } \\
(\%)\end{array}$ \\
\hline PUE & 329 & 429.2 & 308.4 & 439.7 & 14.9 \\
FPUE1 & 350.6 & 431.6 & 307.4 & 438.4 & 17.3 \\
FPUE2 & 349 & 430.2 & 303 & 433 & 19.6 \\
FPUE3 & 333.4 & 430.2 & 298.6 & 433 & 21.2 \\
\hline
\end{tabular}

Flame retardant property of FPUEs: The THR and PHRR of FPUE2 are $15 \mathrm{KJ} / \mathrm{g}$ and $179.5 \mathrm{~W} / \mathrm{g}$, respectively. They are both lower than those of PUE which are $17.1 \mathrm{KJ} / \mathrm{g}$ and $275.6 \mathrm{~W} / \mathrm{g}$. FPUE2 and PUE have the same soft segment, $\mathrm{R}$ and Chain extension coefficient, with the only difference in the types of chain extender. It means that FPUE2 based on $\mathrm{BAFPF}_{6} \mathrm{P}$ shows better flame retardation than PUE based on MOCA; in other words, the introduction of fluorinated chain extender improves the flame retardation.

From FPUE1 to FPUE3, the THR and PHRR decrease from $15.3 \mathrm{KJ} / \mathrm{g}$ and $244.4 \mathrm{~W} / \mathrm{g}$ to $11 \mathrm{KJ} / \mathrm{g}$ and $119.1 \mathrm{~W} / \mathrm{g}$, respectively. The main reason for this is that, from FPUE1 to FPUE3, they all contain the same soft segment and chain extender, but the $\mathrm{R}$ increases from 1.8-2.4, so the increase in the fluorinated chain extender content gradually results in an increase in flame retardation (Fig. 4).

Surface property of FPUEs: The contact angle of PUE with water and ethylene glycol are 66.2 and $51.1^{\circ}$ and the surface tension is $35.77 \mathrm{mN} / \mathrm{m}$, while the surface tension of FPUE1, FPUE2 and FPUE3 is obviously lower. The surface tension of FPUE3 is just $18.18 \mathrm{mN} / \mathrm{m}$, almost reduced $50 \%$ compared with PUE. It shows that the introduction of fluorine to the polyurethane elastomer reduces the surface tension. The main reasons for this is that the $\mathrm{CF}_{3}$ bears relatively low surface energy, so it is easy to migrate to and enrich on the surface, which results in the higher concentration of $\mathrm{CF}_{3}$ groups on the surface than in bulk and then the FPUEs show excellent low surface energy (Table-3).

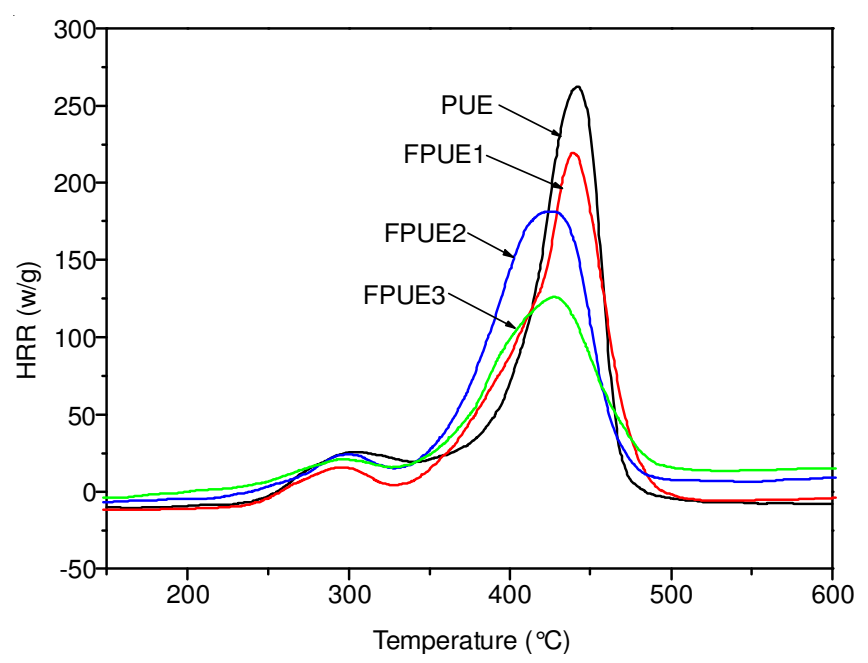

Fig. 4. MCC curves of FPUEs

\begin{tabular}{|c|c|c|c|c|c|}
\hline \multirow{3}{*}{ Sample } & \multicolumn{4}{|c|}{$\begin{array}{c}\text { TABLE-3 } \\
\text { SURFACE PROPERTIES OF FPUES AND PU }\end{array}$} & \\
\hline & \multicolumn{2}{|c|}{ Contact angle $\left(^{\circ}\right)$} & \multicolumn{3}{|c|}{ Surface tension $\left(\times 10^{-3} \mathrm{~N} / \mathrm{m}\right)$} \\
\hline & Water & Ethylene glycol & $\gamma^{d}$ & $\gamma^{p}$ & $\gamma$ \\
\hline PUE & 66.2 & 51.1 & 10.07 & 25.71 & 35.77 \\
\hline FPUE1 & 89.7 & 70 & 15.45 & 6.52 & 21.97 \\
\hline FPUE2 & 98.8 & 77 & 17.64 & 2.47 & 20.11 \\
\hline FPUE3 & 105.5 & 83.5 & 17.12 & 1.06 & 18.18 \\
\hline
\end{tabular}

\section{Conclusion}

2,2-Bis[4-(4-amino-2-trifluoromethylphenoxy)phenyl]hexafluoropropane $\left(\mathrm{BAFPF}_{6} \mathrm{P}\right)$ was synthesized from 2-chlorobenzotrifluoride and 2,2-bis(4-hydroxyphenyl)hexafluoropropane and it was utilized as a chain extender to prepare a series of FPUEs. Through the FTIR and NMR analysis, the results demonstrate the structure of synthetic product is in accord with that of the expected design. The influence of fluorine on thermal stability, flammability and surface properties of the FPUE were investigated. The results show that the introduction of fluorinated chain extender can improve the surface properties efficiently. The surface tension of FPUE3 is almost reduced by $50 \%$ compared with that of PUE. The results from TGA show that the introduction of fluorinated chain extender to the PUE improves the thermal stabilities; the THR and PHRR of FPUE2 are $15 \mathrm{KJ} / \mathrm{g}$ and $179.5 \mathrm{~W} / \mathrm{g}$, respectively, which indicates that the fluorinated chain extender incorporated contributes to improved flame-retardant properties. These properties should make these FPUEs attractive for practical applications.

\section{ACKNOWLEDGEMENTS}

The authors thank the National Natural Science Foundation of China (No. 21004001/B040601) and the National Key Technology R\&D Program (No. 2013BAJ01B05) for their financial support.

\section{REFERENCES}

1. T. Liu and L. Ye, J. Fluor. Chem., 131, 36 (2010).

2. K. Chen and J. Kuo, Macromol. Chem. Phys., 201, 2676 (2000).

3. W.L. Wu, G.C. Yuan, A.H. He and C.C. Han, Langmuir, 25, 3178 (2009).

4. L.F. Wang, Eur. Polym. J., 41, 293 (2005). 